ARTICLE OPEN

\title{
A multinational observational study identifying primary care patients at risk of overestimation of asthma control
}

\author{
Vicky Kritikos ${ }^{1,2 *}$, David Price $\mathbb{D}^{3,4,5}$, Alberto Papi ${ }^{6}$, Antonio Infantino ${ }^{7}$, Bjorn Ställberg ${ }^{8}$, Dermot Ryan $\mathbb{i D}^{3,9}$, Federico Lavorini $\mathbb{1 D}^{10}$, \\ Henry Chrystyn ${ }^{11}$, John Haughney $\mathbb{D}^{12}{ }^{12}$, Karin Lisspers ${ }^{8}$, Kevin Gruffydd-Jones ${ }^{13}$, Miguel Román Rodríguez ${ }^{14}$, \\ Svein Høegh Henrichsen ${ }^{15}$, Thys van der Molen ${ }^{16}$, Victoria Carter (D) $^{3,4}$ and Sinthia Bosnic-Anticevich ${ }^{1,17,18}$
}

Factors related to the discrepancy between patient-perceived and actual disease control remain unclear. Identifying patients at risk of overestimation of asthma control remains elusive. This study aimed to (i) investigate the relationship between patient-reported and actual level of asthma control (ii), compare the characteristics between patients who believe their asthma is well controlled that accurately report 'well-controlled' asthma with those that do not, and (iii) identify factors associated with inaccurately reported 'well-controlled' asthma. A historical, multinational, cross-sectional study using data from the iHARP (initiative Helping Asthma in Real-life Patients) review service for adults with asthma prescribed fixed-dose combination therapy. Data from 4274 patients were analysed. A major discrepancy between patient-reported and Global Initiative for Asthma defined asthma control was detected; $71.1 \%$ of patients who reported 'well-controlled' asthma were inaccurate in their perception despite receiving regular maintenance therapy. Significant differences were noted in age, gender, body mass index, education level, medication use, side effects, attitudes to preventer inhaler use, inhaler technique review and respiratory specialist review between patients who accurately reported 'wellcontrolled' asthma and those who did not. Independent risk factors associated with inaccurately reported 'well-controlled' asthma were: having taken a maximum of 5-12 puffs or more of reliever inhaler on at least one day within the previous 4 weeks; being female; having seen a respiratory specialist more than a year ago (rather than in the previous year); and having required oral corticosteroids for worsening asthma in the previous year. The study highlighted the significant hidden burden associated with under-recognition of poor asthma control, on the part of the patient and the need for targeted interventions designed to address the continuing discrepancy between perceived and actual disease control.

npj Primary Care Respiratory Medicine (2019)29:43; https://doi.org/10.1038/s41533-019-0156-4

\section{INTRODUCTION}

Asthma is one of the most common chronic conditions worldwide, ${ }^{1}$ affecting $\sim 30$ million people in Europe and more than 5 million people in the United Kingdom (UK). ${ }^{2}$ Despite the existence of a global strategy for asthma management, ${ }^{3}$ and availability of national guidelines and effective treatments, ${ }^{4}$ rates of poor asthma control remain high worldwide. ${ }^{5-20}$ Poor asthma control reduces patients' quality of life and productivity, increases health care utilisation and the risk of exacerbations and mortality. $6,8,21$ Further, poor asthma control poses a greater economic burden on individuals, communities and health care systems than controlled disease. 22,23

When it comes to disease control, the patient experience of symptoms over time is extremely important. Unfortunately, this is one of the great challenges in asthma management. Many patients who consider their asthma to be 'well controlled' often overestimate their actual level of asthma control. ${ }^{9,19,24,25}$ While a discrepancy between patient-perceived and actual disease control is frequently reported, the reasons for and the factors related to this disparity remain unclear. Identifying patients at risk of overestimation of asthma control remains elusive.

The ramifications of overestimating level of disease control on the part of the patient are far-reaching. Many patients who mistakenly consider their asthma to be 'well controlled' often accept their symptoms as being part of the 'norm' of having asthma and are unlikely to seek asthma-related information, education or care from health care practitioners (HCPs) ${ }^{26}$ Further, since guideline treatment options are based on patient-reported symptoms, ${ }^{3,4}$ appropriate treatment may not be prescribed if a patient fails to recognise and report poorly controlled symptoms to their HCP. ${ }^{27}$ Patients who do not voice their concerns or underreport troublesome symptoms run the risk of under-treatment and the perpetuation of poor asthma control and a potential increased future risk of adverse outcomes. ${ }^{12}$ This under-reporting of symptoms by patients also emphasises the need for more objective measures such as spirometry and symptom questionnaires in clinical practice.

\footnotetext{
${ }^{1}$ Quality Use of Respiratory Medicines Group, Woolcock Institute of Medical Research, University of Sydney, Sydney, NSW, Australia. ${ }^{2}$ Department of Respiratory and Sleep Medicine, Royal Prince Alfred Hospital, Sydney, NSW, Australia. ${ }^{3}$ Optimum Patient Care, Cambridge, UK. ${ }^{4}$ Observational and Pragmatic Research Institute, Southbank, Singapore. ${ }^{5}$ Academic Primary Care, University of Aberdeen, Aberdeen, UK. ${ }^{6}$ Respiratory Medicine, University of Ferrara, Ferrara, Italy. ${ }^{7}$ Special Interest Respiratory Area, Italian Interdisciplinary Society for Primary Care, Bari, Italy. ${ }^{8}$ Department of Public Health and Caring Sciences, Family Medicine and Preventive Medicine, Uppsala University, Uppsala, Sweden. ${ }^{9}$ Allergy and Respiratory Research Group, Usher Institute of Population Health Sciences and Informatics, University of Edinburgh, Edinburgh, UK. ${ }^{10}$ Department Experimental and Clinical Medicine, University of Florence, Firenze, Italy. ${ }^{11}$ Inhalation Consultancy Ltd, Leeds, UK. ${ }^{12}$ NHS Greater Glasgow \& Clyde R\&D, Glasgow, UK. ${ }^{13}$ Box Surgery, Box, UK. ${ }^{14}$ Primary Care Respiratory Research Unit, Instituto de Investigación Sanitaria de Baleares (IdISBa), Palma, Spain. ${ }^{15}$ Department of Primary Health Care Services, Norwegian Directorate of Health, Oslo, Norway. ${ }^{16}$ Department of Primary Care, University of Groningen, University Medical Centre Groningen, Groningen, Netherlands. ${ }^{17}$ Sydney Medical School, Faculty of Medicine and Health, The University of Sydney, Sydney, NSW, Australia. ${ }^{18}$ Central Sydney Local Area Health District, Sydney, NSW, Australia. *email: vicky.kritikos@sydney.edu.au
} 
In an attempt to improve rates of well-controlled asthma, a number of studies have identified modifiable and unmodifiable risk factors for poor asthma control across different patient populations. ${ }^{28-32}$ While a broad range of risk factors, both clinical and behavioural, have been identified, assessment of asthma control continues to be based on patient-reported symptoms, hence once again highlighting the importance of the relationship between patient-reported and actual disease control among patients in a real-life clinical setting. ${ }^{9,33}$ To date, little is known about factors associated with overestimation of the level of asthma control. From an HCP perspective, it seems critical to be able to identify patients at risk of overestimating their level of asthma control, and thus inaccurately reporting 'well-controlled' asthma. Insight into factors associated with inaccurately reported 'well-controlled' asthma may help HCPs' tailor interventions to patient profiles and help identify effective asthma management strategies for the future. We hypothesised that factors associated with inaccurately reported 'well-controlled' asthma among adults with a current physician diagnosis of asthma are patient-related, and some factors are potentially modifiable.

This research aimed to use patient data from the iHARP (initiative Helping Asthma in Real-life Patients) database ${ }^{34}$ to gain deeper insight into the discrepancy between perceived and actual disease control. The specific objectives were to (i) investigate the relationship between patient-reported and actual level of asthma control, (ii) compare the demographic, clinical and attitudinal/ behavioural characteristics between patients who believe their asthma is well controlled that accurately report 'well-controlled' asthma with those that overestimate their level of asthma control and inaccurately report 'well-controlled' asthma and (iii) identify factors associated with inaccurately reported 'well-controlled' asthma.

\section{RESULTS}

\section{Patients}

There were 4274 adult patients with asthma-prescribed FDC ICS/ LABA therapy in the iHARP database between June 2011 and December 2014. The study cohort included 2574 (60.2\%) from the UK, 652 (15.3\%) from the Netherlands, 527 (12.3\%) from Spain, 403 (9.4\%) from Italy, 62 (1.5\%) from Sweden, 36 (0.8\%) from Norway and $20(0.5 \%)$ from France. The mean (SD) age of patients was 50.9 (14.3) years, $2600(60.8 \%)$ were females, 1416 (33.1\%) were obese (body mass index $\geq 30 \mathrm{~kg} / \mathrm{m}^{2}$ ) and 553 (12.9\%) were current smokers.

Among the 4274 patients, 1296 (30.3\%) patients had controlled asthma, $1912(44.7 \%)$ had partially controlled asthma and 1066 (25.0\%) uncontrolled asthma using Global Initiative for Asthma (GINA)-defined criteria (Table 1). When asked about their asthma in the past 4 weeks, 2582 (60.4\%) patients believed their asthma was 'well controlled'. Of this subset of patients, only 745 (28.9\%) patients accurately reported 'well-controlled' asthma (Group A) and 1837 (71.1\%) inaccurately reported 'well-controlled' asthma (Group B), that is, they overestimated their level of asthma control (Table 1).

Of the 1692 (39.6\%) patients who believed their asthma was 'not well controlled' in the past 4 weeks, 1141 (67.4\%) accurately reported 'not-well-controlled' asthma and 551 (32.6\%) underestimated their level of asthma control (Table 1). The incidence of accurately reported 'well controlled' asthma was significantly lower than that of accurately reported 'not-well-controlled' asthma (28.9\% vs. $67.4 \%, p=0.010)$.

Characteristics of patients who inaccurately reported 'wellcontrolled' asthma

Patients in Group B who overestimated their asthma control level, that is, inaccurately reported 'well-controlled' asthma were significantly more likely to be older, female, obese, or lacking a university degree than those in Group A who accurately estimated 'well-controlled' asthma (Table 2). In the week prior to iHARP data collection, $34.2 \%$ of Group B patients experienced asthma symptoms for $>2$ days, 466 (25.4\%) indicated that symptoms interfered with their daily activities, 526 (28.6\%) had night awakenings due to asthma and $769(41.9 \%)$ used their relievers $\geq 3$ times (Table 2), with 261 (14.2\%) indicating they used their relievers $\geq 10$ times. In the 4 weeks prior to data collection, the incidence of taking 5-12 puffs or more of reliever in one day was significantly higher among patients in Group $B$ than those in Group A (13.1\% vs. 1.2\%, $p<0.001$ ) (Table 3). In addition, Group B patients were significantly more likely to report having experienced acute exacerbations requiring short-term courses of oral corticosteroids and asthma-related hospitalisations in the previous year compared with patients in Group A (Table 3).

Patient-reported inhaler review by an HCP in the previous year, oropharyngeal effects during the inspiration phase of preventer inhaler use and side effects from asthma therapy were more common among patients in Group B than those in Group A (Table 4). Compared to patients in Group A, patients in Group B were significantly more likely to be in agreement that they need to take their inhaler(s) in order for their asthma to be 'well controlled' and were significantly more likely to have been reviewed by a respiratory specialist more than a year ago rather than in the previous year (Table 4). The incidence of accurately reported 'wellcontrolled' asthma was significantly higher among patients who had seen a respiratory specialist in the previous year than those who had seen a respiratory physician more than a year ago $(31.8 \%$ vs. $20.8 \%, p<0.001$ ).

Factors associated with inaccurately reported 'well-controlled' asthma

Univariate logistic regression models were developed using independent variables as risk factors for inaccurately reported

Table 1. GINA-defined asthma control overall and by patient-reported level of asthma control.

\begin{tabular}{llcl}
\hline GINA-defined asthma control $^{\mathrm{a}}$ & Total, $N(\%)(N=4274)$ & \multicolumn{1}{l}{ Patient-reported level of asthma control $(N=4274)$} \\
\cline { 2 - 4 } & & Well controlled, $n(\%)(n=2582)$ & Not well controlled, $n(\%)(n=1692)$ \\
\hline Controlled & $1296(30.3)$ & $745(28.9)$ & $551(32.6)$ \\
Partially controlled & $1912(44.7)$ & $538(209(50.3)$ & $613(36.2)$ \\
Uncontrolled & $1066(25.0)$ & $528(31.2)$
\end{tabular}

Note: Data are shown as percentage of patients, $N=4274$; patients who reported 'well-controlled' asthma, $n=2582$, and those who reported 'not-wellcontrolled' asthma, $n=1692$

aGINA (Global Initiative for Asthma) criteria: daytime symptoms (>2 days/week); need reliever inhaler (>2 days/week); any limitation in daytime activity; any night wakening due to asthma in the past week. The presence of these four criteria determined the asthma control level: none of the above (controlled); 1 or 2 of the above (partially controlled); 3 or 4 of the above (uncontrolled) 


\begin{tabular}{|c|c|c|c|}
\hline \multirow[t]{3}{*}{ Characteristic } & \multicolumn{2}{|c|}{$\begin{array}{l}\text { Patient reported 'well- } \\
\text { controlled' asthma }(N=2582)\end{array}$} & \multirow[t]{3}{*}{$p$ Value $^{*}$} \\
\hline & Group A & Group B & \\
\hline & $\begin{array}{l}\text { Accurately } \\
\text { reported } \\
(n=745)\end{array}$ & $\begin{array}{l}\text { Inaccurately } \\
\text { reported } \\
(n=1837)\end{array}$ & \\
\hline Age, mean (SD) & $50.0(14.4)$ & $51.4(14.2)$ & $0.02^{\mathrm{b}}$ \\
\hline \multicolumn{4}{|l|}{ Age range (years), $n(\%)$} \\
\hline $18-29$ & $74(9.9)$ & $171(9.3)$ & \multirow[t]{3}{*}{$0.04^{a}$} \\
\hline $30-49$ & $271(36.4)$ & $583(31.7)$ & \\
\hline$\geq 50$ & $400(53.7)$ & $1083(59.0)$ & \\
\hline \multicolumn{4}{|l|}{ Gender, $n(\%)$} \\
\hline Female & $267(35.8)$ & $1326(72.2)$ & \multirow{2}{*}{$<0.001^{\mathrm{a}}$} \\
\hline Male & $478(64.2)$ & $511(27.8)$ & \\
\hline \multicolumn{4}{|l|}{ Body mass category ${ }^{c}, n(\%)$} \\
\hline Underweight & $12(1.6)$ & $21(1.1)$ & \multirow[t]{4}{*}{$<0.001^{\mathrm{a}}$} \\
\hline Normal & $249(33.4)$ & $563(30.6)$ & \\
\hline Overweight & $300(40.3)$ & $601(32.7)$ & \\
\hline Obese & $184(24.7)$ & $652(35.5)$ & \\
\hline \multicolumn{4}{|l|}{ Smoking status, $n(\%)$} \\
\hline Current smoker & $72(9.7)$ & $226(12.3)$ & \multirow[t]{4}{*}{$0.08^{\mathrm{a}}$} \\
\hline Ex-smoker & $219(29.4)$ & $566(30.8)$ & \\
\hline Non-smoker & $454(60.9)$ & $1045(56.9)$ & \\
\hline $\begin{array}{l}\text { Education }{ }^{d} \text {, known } \\
\text { status, } n(\%)\end{array}$ & $(n=651)$ & $(n=1500)$ & \\
\hline PG or professional degree & $30(4.6)$ & $63(4.2)$ & \multirow[t]{5}{*}{$<0.001^{\mathrm{a}}$} \\
\hline University degree ${ }^{\mathrm{e}}$ & $224(34.4)$ & $508(33.9)$ & \\
\hline Secondary education ${ }^{\mathrm{e}}$ & $278(42.7)$ & $772(51.5)$ & \\
\hline Primary education ${ }^{\mathrm{e}}$ & 97 (14.9) & $131(8.7)$ & \\
\hline None & $22(3.4)$ & $26(1.7)$ & \\
\hline \multicolumn{4}{|c|}{$\begin{array}{l}\text { PG post graduate, } S D \text { standard deviation } \\
{ }^{*} p \text { Value of Group A versus Group B } \\
\text { Note: Percentages are column percentages } \\
{ }^{a} X^{2} \text { test for independence } \\
{ }^{b} \text { Mann-Whitney } U \text { test } \\
\text { CUnderweight } \mathrm{BMI} \leq 18.49 \mathrm{~kg} / \mathrm{m}^{2} \text {; normal } \mathrm{BMI}=18.5-24.99 \mathrm{~kg} / \mathrm{m}^{2} \text {; over- } \\
\text { weight } \mathrm{BMI}=25-29.99 \mathrm{~kg} / \mathrm{m}^{2} ; \text { obese } \mathrm{BMI} \geq 30 \mathrm{~kg} / \mathrm{m}^{2} \\
{ }^{\mathrm{d}} \text { Estimation of 'well-controlled' asthma by education reported as } n(\%) \text { of } \\
\text { known status } \\
{ }^{\text {e} C o m p l e t e d ~ o r ~ s o m e ~ e d u c a t i o n ~}\end{array}$} \\
\hline
\end{tabular}

'well-controlled' asthma. The univariate models considered all 12 variables (age group, gender, body mass index, education level, highest number of puffs of reliever taken in one day, oral corticosteroid use for worsening asthma, hospitalisation due to asthma, inhaler review by an HCP, respiratory specialist review, side effects from preventer inhaler use, oropharyngeal effects during the inspiration phase and need to take inhaler(s) for asthma to be well controlled), which were associated with inaccurately reported 'well-controlled' asthma. The univariable logistic regression results for the risk of inaccurately reported 'well-controlled' asthma are shown in Table 5. There were no correlations between the univariate predictors; therefore, they were subsequently included for analysis in the multivariate logistic regression model. The multivariable logistic regression model was statistically significant $\left(x^{2}=200.37\right.$, d.f. $\left.=13, p<0.001\right)$, explaining $33.5 \%$ (Nagelkerke $R^{2}$ ) of the overall variance. Patients who
Table 3. Asthma symptoms and indicators of exacerbations by accurately versus inaccurately reported 'well-controlled' asthma.

\begin{tabular}{ll}
$\begin{array}{l}\text { Patient reported 'well-controlled' asthma } \\
(N=2582)\end{array}$ & $p$ Value* \\
\hline Group A & Group B \\
$\begin{array}{ll}\text { Accurately } & \text { Inaccurately reported } \\
\text { reported }(n=745) & (n=1837)\end{array}$
\end{tabular}

Asthma symptoms (past 7 days)

Daytime symptoms, $n$ (\%)

\begin{tabular}{|c|c|c|}
\hline None & $610(81.9)$ & $709(3$ \\
\hline $1-2$ days & $135(18.1)$ & $500(2$ \\
\hline$\geq 3$ days & 0 & 628( \\
\hline \multicolumn{3}{|c|}{ Activity limitations due to asthma, $n(\%)$} \\
\hline None & $745(100.0)$ & $1371(7$ \\
\hline$\geq 1$ day & 0 & 466 \\
\hline \multicolumn{3}{|c|}{ Night waking, $n(\%)$} \\
\hline None & $745(100.0)$ & $1311(7$ \\
\hline$\geq 1$ night & 0 & $526(2$ \\
\hline \multicolumn{3}{|c|}{ Reliever needed for symptoms, $n(\%)$} \\
\hline Not used & $607(81.5)$ & 713 \\
\hline $1-2$ times & $136(18.2)$ & 355 \\
\hline$\geq 3$ times & $2(0.3)$ & 769 \\
\hline
\end{tabular}

Highest number of puffs of reliever inhaler taken in $1 \mathrm{day}^{\mathrm{b}}, n(\%)$

$$
\begin{array}{lcrl}
0-4 & 736(98.8) & 1596(86.9) & <0.001^{\mathrm{a}} \\
5-12 \text { or more } & 9(1.2) & 241(13.1) &
\end{array}
$$

Acute exacerbations (past 12 months)

Oral corticosteroid use for worsening asthma, $n(\%)$

$\begin{array}{lcc}\text { None } & 610(81.9) & 1384(75.4) \\ 1 & 98(13.2) & 263(14.3) \\ \geq 2 & 37(5.0) & 188(10.3)\end{array}$

$<0.001^{a}$

Emergency department visit due to asthma, $n$ (\%)

\begin{tabular}{lcrl} 
None & $694(93.2)$ & $1680(91.5)$ & $0.39^{\mathrm{a}}$ \\
1 & $37(5.0)$ & $111(6.0)$ & \\
$\geq 2$ & $14(1.8)$ & $46(2.5)$ & \\
Hospitalisation due to asthma, $n(\%)$ & & $0.010^{\mathrm{a}}$ \\
None & $730(98.0)$ & $1751(95.4)$ & \\
1 & $14(1.9)$ & $64(3.5)$ & \\
$\geq 2$ & $1(0.1)$ & $21(1.1)$ & \\
\hline
\end{tabular}

${ }^{*} p$ Value of Group A versus Group B

${ }^{\text {aPearson's }} X^{2}$ test for independence

bHighest number of puffs of reliever inhaler use, in response to the question: 'In the past 4 weeks, what was the highest number of puffs in 1 day you took of the reliever inhaler?' with response options $0,1-4$ puffs and $5+$ puffs

inaccurately reported 'well-controlled' asthma were 14 times more likely to have taken 5-12 puffs or more of reliever in 1 day within the previous 4 weeks (odds ratio $(O R)=14.02,95 \%$ confidence interval $(\mathrm{Cl}): 4.19-47.00, p \leq 0.001)$, nine times more likely to be female (OR $=9.38,95 \% \mathrm{Cl}: 6.23-14.13, p<0.001)$, nearly nine times more likely to have required oral corticosteroids for worsening asthma in the previous year (OR $=8.80,95 \% \mathrm{Cl}: 2.97-26.06, p \leq$ 0.001 ) and nearly four times more likely to have seen a respiratory specialist more than a year ago rather than in the previous year $(\mathrm{OR}=3.63,95 \% \mathrm{Cl}: 2.05-6.41, p<0.001)$ (Table 6). There was a significant interaction between oral corticosteroid use and respiratory specialist review. Among patients who had seen a 
Table 4. Clinical characteristics by accurately versus inaccurately reported 'well-controlled', asthma.

\begin{tabular}{|c|c|c|c|}
\hline & \multicolumn{2}{|c|}{ Patient reported 'well-controlled' asthma $(N=2582)$} & \multirow[t]{2}{*}{$p$ Value* } \\
\hline & Accurately reported $(n=745)$ & Inaccurately reported $(n=1837)$ & \\
\hline Patient-reported rhinitis symptoms, $n$ (\%) & $480(64.4)$ & $1194(65.1)$ & $0.75^{\mathrm{a}}$ \\
\hline Patient-reported prior inhaler review by $\mathrm{HCP}^{\mathrm{b}}, n(\%)$ & $348(46.7)$ & $1027(56.0)$ & $<0.001^{\mathrm{a}}$ \\
\hline Patient self-assessment of inhaler technique, $n(\%)$, known & $(n=730)$ & $(n=1816)$ & \\
\hline Good to excellent & $594(81.4)$ & $1423(78.4)$ & \\
\hline Patient-reported respiratory specialist review & $(n=620)$ & $(n=1693)$ & \\
\hline Never & $242(39.0)$ & $430(25.4)$ & $<0.001^{\mathrm{a}}$ \\
\hline In the previous year & $107(17.3)$ & $230(13.6)$ & \\
\hline More than a year ago & $271(43.7)$ & $1033(61.0)$ & \\
\hline Good & $460(63.5)$ & $1124(62.7)$ & \\
\hline Adherence to therapy in the Netherlands ${ }^{d}, n(\%)$, known & $(n=22)$ & $(n=49)$ & \\
\hline Poor & $7(31.8)$ & $5(10.2)$ & $0.06^{\mathrm{a}}$ \\
\hline Borderline & $5(22.7)$ & $9(18.4)$ & \\
\hline Good & $10(45.5)$ & $35(71.4)$ & \\
\hline Patient-reported side effects ${ }^{\mathrm{e}}, n(\%)$, known & $(n=721)$ & $(n=1793)$ & \\
\hline None & $507(70.3)$ & $903(50.4)$ & $<0.001^{\mathrm{a}}$ \\
\hline 1 & $146(20.2)$ & $434(24.2)$ & \\
\hline 2 & $52(7.2)$ & $276(15.4)$ & \\
\hline$\geq 3$ & $16(2.2)$ & $180(10.0)$ & \\
\hline Patient-reported oropharyngeal effects ${ }^{g}, n(\%)$ known & $(n=711)$ & $(n=1766)$ & \\
\hline I find my inhaler easy to use & $649(90.0)$ & $1616(90.0)$ & $0.98^{\mathrm{a}}$ \\
\hline Taking regular asthma medication does not worry me & $563(78.1)$ & $1422(79.2)$ & $0.55^{\mathrm{a}}$ \\
\hline \multicolumn{4}{|c|}{$\begin{array}{l}\text { HCP health care practitioner } \\
\text { *p Value of Group A versus Group B } \\
\text { a Pearson's } X^{2} \text { test for independence } \\
\text { bIn the year before an iHARP asthma review } \\
\text { 'Number (\%) calculated as percentage of patients from the UK, Italy, Spain, Sweden, France and Norway reported as } n \text { (\%) of known status } \\
\text { 'Number (\%) calculated as percentage of patients from the Netherlands } \\
\text { 'Patient-reported side effects from preventer inhaler use, in response to the question: 'Do you experience any of these side effects from your preventer } \\
\text { inhaler?' with 'yes' or 'no' responses for the following side effects: continual sore mouth/throat; oral thrush; bruising; hoarse voice; abnormal weight gain and } \\
\text { cough. Patients could indicate more than one side effect } \\
\text { fPatient-reported oropharyngeal effects during inspiration phase of preventer inhaler use, in response to the question: 'When you use your preventer inhaler, } \\
\text { do you feel a sensation at the back of your throat?; do you sometimes feel a need to cough?; do you feel your medication is deposited at the back of your } \\
\text { throat?' with yes' or 'no' response options. Patients could indicate more than one experience }\end{array}$} \\
\hline
\end{tabular}

respiratory specialist in the previous year, those who had not required oral steroids in the previous 12 months were more likely to accurately report 'well-controlled' asthma compared to patients who had required oral steroid use. Among patients who had not required oral steroids in the previous 12 months, those who had seen a respiratory specialist in the previous year were more likely to accurately report 'well-controlled' asthma compared to those who had seen a respiratory specialist more than a year ago (Table 6).

\section{DISCUSSION}

This research, to our knowledge, is the first to explore the factors that are associated with inaccurately reported 'well-controlled' asthma among a large cohort of adult patients who believe their asthma is well controlled and are managed in primary care. In this study, only $30.3 \%$ of patients had good asthma symptom control based on GINA-defined criteria despite receiving fixed-dose combination therapy. However, $60.4 \%$ of patients considered their asthma to be 'well controlled', and of those patients, less 
Table 5. Univariable associations between patient characteristics and inaccurately reported 'well-controlled' asthma.

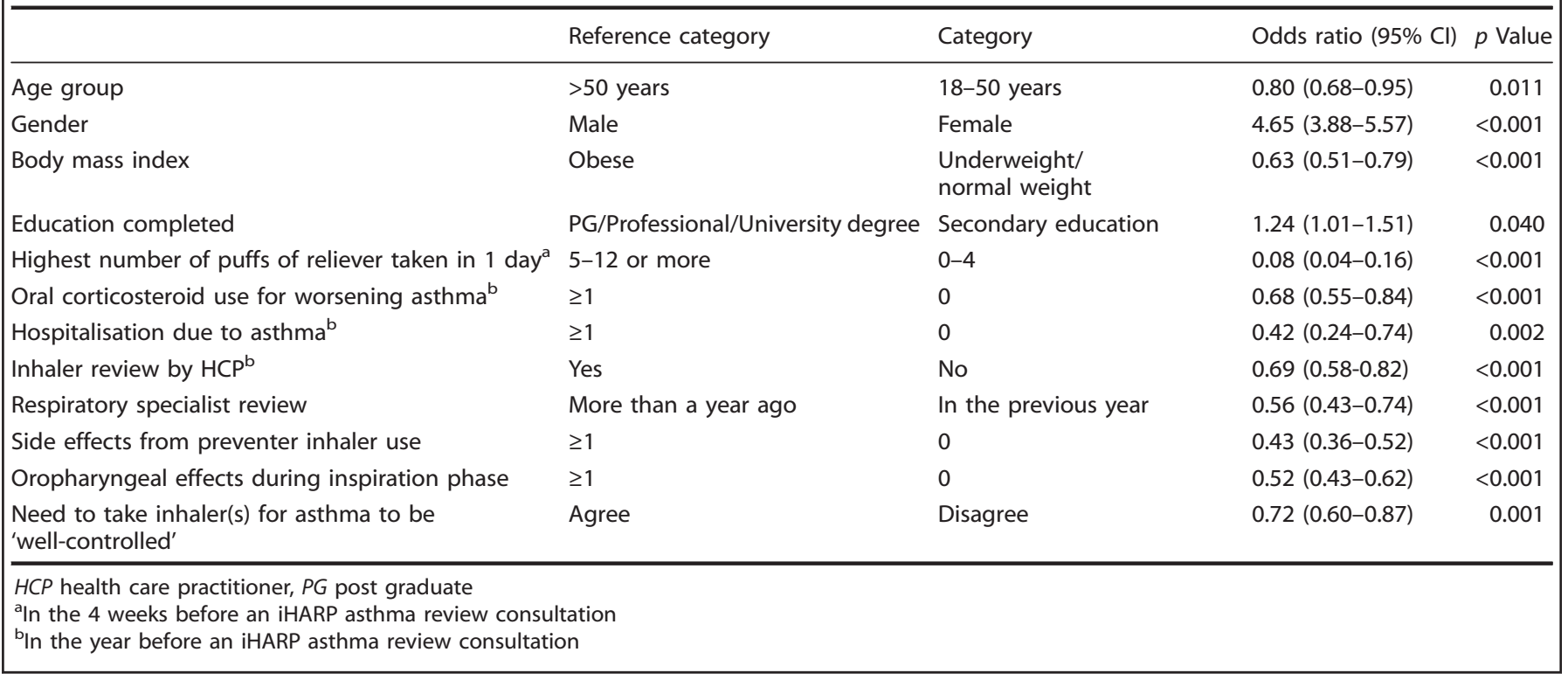

than one-third were accurate in reporting well-controlled asthma. Our findings revealed that the incidence of accurately reported 'well-controlled' asthma was significantly lower than that of accurately reported 'not-well-controlled' asthma. The study provided insight into the 'silent' burden of asthma from the patient's perspective and highlights the potential underrecognition of the increased future risk associated with inaccurately reported well-controlled asthma. Independent risk factors associated with inaccurately reported 'well-controlled' asthma were: having taken a maximum of 5-12 puffs or more of reliever inhaler on at least one day within the previous 4 weeks; being female; having seen a respiratory specialist more than a year ago (rather than in the previous year) and having required oral corticosteroids for worsening asthma in the previous year.

This study revealed a major discrepancy between patientreported and GINA-defined control and a high incidence of inaccurately reported 'well-controlled' asthma. While the discrepancy detected in this study is consistent with findings from recent online surveys across Europe, ${ }^{17,18,24}$ Asia, ${ }^{19}$ Australia, ${ }^{12}$ Latin America, Canada and the United States, ${ }^{13,15,17}$ this study is the first to identify factors associated with this discrepancy and highlights the implications for practice. In summary, this study identified that for patients who report good asthma control, $70 \%$ will be inaccurate in their perception. From both the patient and HCP perspective, this presents a challenge and questions the patient's ability to self-assess their asthma and then self-management. From the HCP perspective, it questions the value of asking a patient about their perception of their asthma control or relying on the patient to report uncontrolled disease. It therefore highlights the need to question the patient about their asthma using validated asthma control questionnaires and to be proactive in reviewing the patient's asthma symptom control and future risk, even when the patient does not recognise this need. This potentially presents a series of HCP-patient relational issues.

Our study provided key insights into the significant increased future risk associated with under-recognition of poor asthma control; that is, patients who overestimate their level of asthma control are more likely to have experienced asthma exacerbations, asthma-related hospitalisations, oropharyngeal effects and/or side effects from asthma therapy, despite having received asthma care and having had their inhaler technique checked in the past. This is somewhat remarkable as these patients report a significant burden of symptoms and medication use: nighttime symptoms, limitations in daily activities, oral corticosteroid use and high dose and/or frequency of short-acting $\beta$-agonist (SABA) reliever use, which can increase their future risk of adverse outcomes. ${ }^{3,19,35}$ Importantly, this study revealed that most patients who inaccurately reported 'well-controlled' asthma are actually doing what they need to do to manage their asthma in accordance with guideline recommendations; ${ }^{3,4,36}$ that is, they have good medication adherence, hold strong beliefs about the need to take their inhalers for their asthma to be well controlled and are not worried about taking regular asthma medication. These findings suggest that patients are 'taking control' of their asthma by doing what they need to do; this flags that they may be interpreting 'asthma control' as a personal self-management behaviour (i.e. a verb) rather than a disease outcome (i.e. a noun). This has implications for asthma management practices and patient education, with the need not only to address the perception discrepancy but also for new terminology to promote a shared understanding of asthma symptom control between patients and HCPs.

Identification of independent risk factors for inaccurately reported well-controlled asthma among adults with moderate-severe asthma indicated that these factors are related to patient demographics, rescue medication use and specialist health care under-utilisation; being female, having taken 5-12 puffs or more of reliever inhaler in one day within the previous 4 weeks, having required oral corticosteroids for worsening asthma in the previous year and having seen a respiratory specialist more than a year ago rather than in the previous year. In our study, a significantly higher proportion of females inaccurately reported 'well-controlled' asthma compared to males $(83.2 \%$ vs. $51.7 \%, p<0.001)$, which parallels previous findings that females are more likely to have suboptimal levels of asthma control ${ }^{20}$ and more likely to be at risk of making serious inhalation technique errors that are linked to poor asthma control. ${ }^{37,38}$ Our findings add to the body of 'gender-related' evidence, and suggest that the self-management tools currently available are not meeting the needs across the genders. There is clearly a need to focus more on giving females the tools that will enable them to become better self-managers of their asthma.

In this study, patients who overestimated their level of asthma control were 14 times more likely to have taken a maximum of 5-12 puffs or more of SABA reliever per day in the previous 
V. Kritikos et al.

Table 6. Logistic regression predicting likelihood of inaccurately reporting 'well-controlled' asthma.

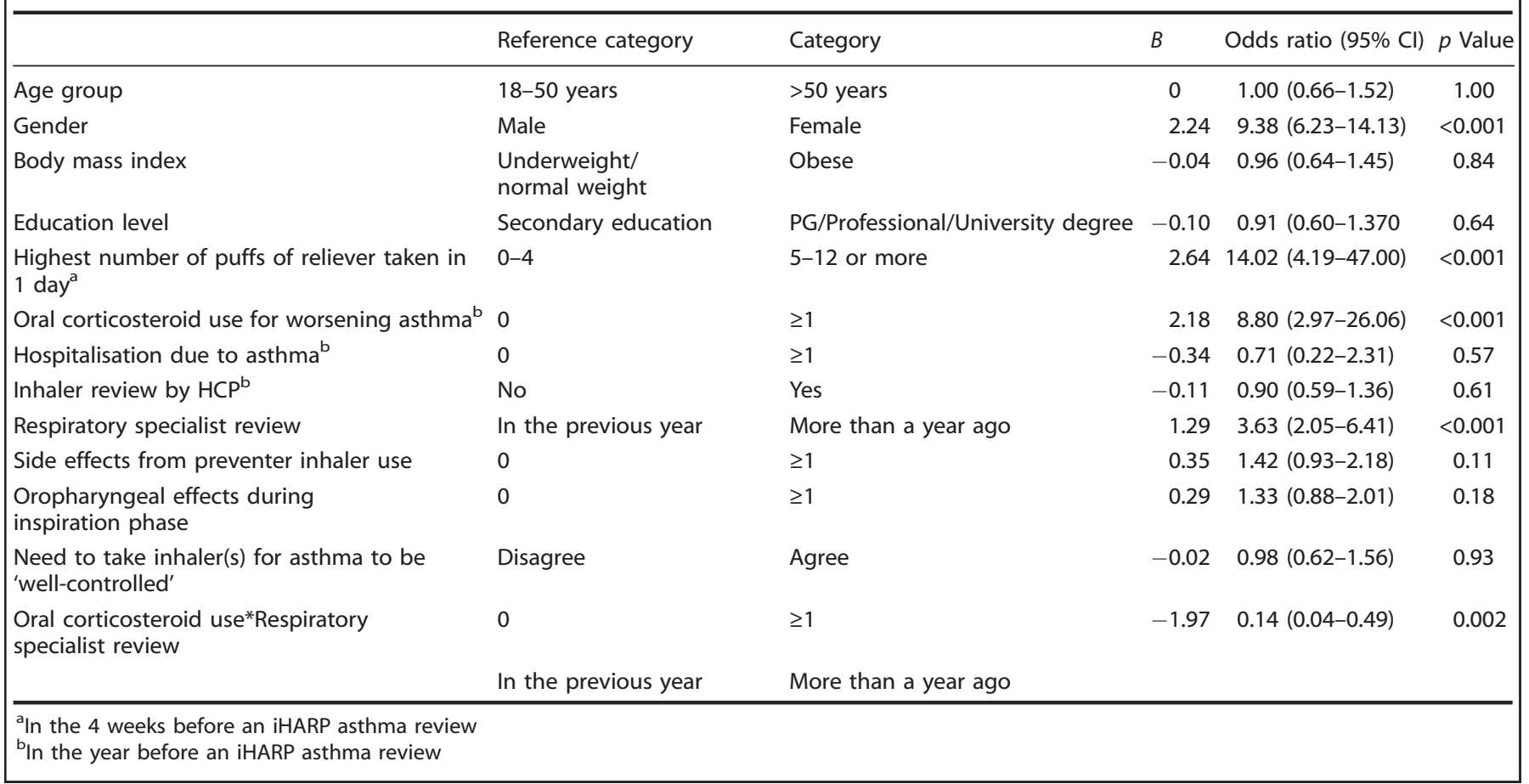

4 weeks. This dose of SABA reliever is by far above what is expected and recommended in practice guidelines; that is, 1-2 puffs of SABA as needed for symptom relief during maintenance treatment in asthma. ${ }^{3,4}$ Overuse of SABA may itself potentially contribute to poor asthma control, ${ }^{39}$ increased risk of exacerbations $^{40,41}$ and fatal asthma. ${ }^{42}$ It has been well documented that with chronic or high-dose exposure, $\beta$-agonists demonstrate proinflammatory effects, rebound bronchoconstriction and toxicity that can masquerade as worsening asthma. ${ }^{43}$ Further, where overuse is associated with rebound bronchoconstriction, patients will often respond by taking even more SABA medication, thereby entering a vicious cycle of increasing use and progressively worsening symptoms. ${ }^{43,44}$ Our findings indicate a complete misunderstanding of the use of SABA relievers or what we are asking as HCPs, and a lack of awareness of the potential for SABA toxicity to be a significant contributor to poor asthma control. It highlights the deficiency in asking simply on how many times/ days per week a patient has used their SABA reliever over the past 4 weeks. Our findings suggest a need for reconsideration of guideline questions that refer to SABA use, and better education of patients, particularly those who have used high doses in the emergency department for acute asthma and continue to use high doses when they have breakthrough symptoms thereafter. In addition, patients who had overestimated their control level were almost nine times more likely to have used oral steroids for worsening symptoms in the previous 12 months reflecting a 'rescue' rather than a 'prevention' of symptoms approach to asthma management, which is consistent with previous findings, ${ }^{19}$ and not without consequences. ${ }^{45,46}$

Inaccurately reported 'well-controlled' asthma was almost four times more likely in patients who had seen a respiratory specialist more than a year ago rather than in the previous year. Our study found that accurately reported 'well-controlled' asthma was significantly more likely among patients who had seen a respiratory specialist in the previous year versus more than a year ago, and even more likely among a subset of patients who had not required oral steroids in the previous 12 months, suggesting that specialist referral in the previous year may help improve the discrepancy between patient-perceived and actual disease control. While specialist referral can be effective in improving asthma management, reducing the risk of severe exacerbations and reducing the number of hospitalisations and the risk of future hospitalisations, ${ }^{47}$ there are many barriers that may impede the referral process. These need to be addressed and include overestimation of patients' actual asthma control by physicians, lack of awareness of guidelines by physicians, lack of adherence to referral guidelines by physicians, communication difficulties between patients and physicians with disparities between patient expectations and experiences with HCPs, financial disincentives for practice stakeholders and low availability of specialists to provide advanced patient care. ${ }^{9,20,24,48}$

Importantly, this study suggests that patient's perception of their level of asthma control is not linked to preventer medication taking behaviour, as there was no significant difference in adherence rates to fixed-dose combination therapy using the 5-item Medication Adherence Report Scale (MARS) between patients who accurately and inaccurately reported well-controlled asthma. Patient's perception of their level of asthma control could be influenced by other factors not considered in the analysis, such as ownership of a current written asthma action plan, inhaler technique, knowledge about asthma and trigger factors, asthma-related quality of life, illness perceptions or psychological dysfunction., ${ }^{9,32}$ Another possible explanation for our findings, is that the MARS may have poor precision and overestimated adherence rates to preventer medication among this patient population.

The strengths of the study are its large sample size, observational design, real-world evidence, global focus and comprehensiveness, including objective and patient-reported outcomes. This study design enabled the exploration of a heterogeneous, representative population of general practitioner-managed patients with an asthma diagnosis, who were prescribed combination preventer therapy; as this is the most commonly used treatment for asthma, it is likely the findings are generalisable in primary care. There are some potential limitations 
to this study, which are associated with the cross-sectional study design, which does not allow us to infer cause and effect, and a reliance on patient recall for self-reported symptoms, exacerbations and medication behaviour that may have been under- or over-stated by patients. Additionally, although there were criteria to exclude people with chronic obstructive pulmonary disease (COPD), and given that many people were aged 50 years or more with a past or current history (and a greater risk of COPD), it may have been possible that people with both asthma and COPD were included and could have biased the results. Another limitation of this study relates to the use of an international dataset and possible confounding caused by inter-country differences in how disease outcomes are measured and recorded (e.g. the Netherlands does not use the MARS to assess adherence). A further limitation of this study relates to the high variability in responses caused by recruitment over several countries. Finally, while significant predictors were identified in our multivariate logistic regression model, the overall variance explained by the model (33.5\%) was relatively low, suggesting other factors not considered in the current analyses may correlate with inaccurately reported 'well-controlled' asthma and reiterating the need for further research in this area. Despite these limitations, this research provided new insight by utilising a structured in-depth asthma review approach and helped in identifying several risk factors associated with inaccurately reported 'well-controlled' asthma, which when addressed may help reduce the discrepancy between actual and perceived disease control, improve the incidence of well-controlled asthma and reduce the burden of disease.

The study identified factors associated with patient's overestimation of their actual level of asthma and highlighted the significant hidden burden associated with under-recognition of poor asthma control, on the part of the patient. It raises the question about the causes for this under-recognition and questions the way in which we ask patients about asthma control. While some of the factors associated with under-recognition may be modifiable, there is an urgent need for targeted interventions that include new strategies, measures and terminology designed to address the continuing discrepancy between perceived and actual disease control. Future qualitative research should explore the causes for under-recognition of poor asthma control as unless we are able to support patients to better align their perception of their asthma with their actual level of asthma control, we will continue to face some fundamental challenges with the management of asthma, and the increased risk of adverse outcomes associated with the poor self-management of this chronic respiratory disease.

\section{METHODS}

Data source

This historical, cross-sectional observational study used anonymised patient data from the iHARP database, an international database comprising anonymised data from practices receiving the iHARP asthma review service. Data were collected prospectively between June 2011 and December 2014 in participating primary care practices in Australia and seven European countries (the United Kingdom (UK), Italy, Spain, France, the Netherlands, Norway and Sweden). The data included patient demographics and results from respiratory reviews led by trained practitioners and asthma questionnaires completed by patients on the day of the iHARP asthma review. For patients assessed within the UK, these data were linked to clinical, diagnostic and prescribing information from electronic medical records.

Each of the participating sites obtained ethics approval for the iHARP asthma review service according to their country-specific requirements. All participants provided informed consent. The study was registered with the European Network of Centres for Pharmacoepidemiology and Pharmacovigilance (ENCEPP) (as ENCePP/SDPP/9651).

\section{Cohort definition}

To be eligible for iHARP review, patients had to have a current diagnosis of asthma, received $\geq 2$ fixed-dose combination inhaled corticosteroid and long-acting $\beta_{2}$ agonist (FDC ICS/LABA) therapy in the year before the review, and their data had to meet standards of the International Primary Care Respiratory Group, ${ }^{49}$ Quality and Outcomes Framework recommendations $\mathrm{s}^{50}$ and GINA strategy report at the time of data collection. ${ }^{51}$ Patients were excluded if they had a diagnosis of COPD or any other chronic respiratory disease other than asthma, or if they were receiving long-term systemic asthma treatment (e.g. maintenance oral corticosteroids, theophylline, leukotriene receptor antagonists or anti-lgE therapy), or oral corticosteroids and/or antibiotics for a lower respiratory condition in the 2 weeks before data collection. Our study cohort was restricted to the subset of patients from the database who were at least 18 years of age from participating practices across seven European countries.

\section{Study data and assessments}

Demographics and data from patient-completed asthma questionnaires were obtained from the iHARP database. Asthma control was assessed using the four GINA criteria at the time, which asked patients if they experienced the following during the week preceding the review visit: daytime symptoms (more than twice/week); any night wakening due to asthma; need reliever inhaler (more than twice/week); any limitation in daytime activity. The presence of these four criteria determined the asthma control category as follows: none of the above (controlled); 1 or 2 of the above (partially controlled); 3 or 4 of the above (uncontrolled). ${ }^{51}$

Patient perceptions of their recent asthma control were elicited by asking the patient to respond to the following question: 'In the past 4 weeks, did you believe that your asthma was 'well controlled'?' with 'yes' or 'no' response options. Patients were categorised in Group A if they indicated they believed that their asthma was 'well controlled' AND had controlled asthma as assessed by GINA-defined criteria. Patients were categorised in Group B if they indicated they believed that their asthma was 'well controlled' BUT had partially controlled or uncontrolled asthma according to GINA-defined criteria.

Self-reported rhinitis symptoms were assessed with a single question derived from the Allergic Rhinitis and its Impact on Asthma (ARIA) and IPCRG definition of rhinitis; ${ }^{52,53}$ 'Do you have any of these symptoms: itchy, runny, blocked nose or sneezing when you don't have a cold?', with responses ranging from, 0 ('no'), 1 ('occasionally and little bother'), 2 ('occasionally but quite a bother'), 3 ('most days but little bother'), or 4 ('most days and a lot of bother'). Responses 1 and 3 were classified under 'mild' rhinitis and responses 2 and 4 under 'moderate-severe' rhinitis.

All patients were asked if their inhaler technique had been reviewed in the previous year by an HCP, and patients were asked to self-assess their inhaler technique using a Likert scale with scores ranging from 1 ('I think my inhaler technique is very poor') to 6 ('I think my inhaler technique is excellent'). Patients were also asked if they had been reviewed by a specialist respiratory doctor or nurse outside the practice with three response options; 'in the previous year', 'more than a year ago' or 'never'.

Beliefs and perceptions about asthma therapy were assessed with three items from the Beliefs about Medicines Questionnaire that were adapted for use in asthma: ${ }^{54}$ 'I need to take my inhaler(s) for my asthma to be 'well controlled'; 'I find my inhalers easy to use' and 'Taking regular asthma medication does not worry me," with ratings on a 6-point Likert scale from 1 (strongly agree) to 6 (strongly disagree).

Self-reported adherence to maintenance therapy was assessed for patients from the UK, Italy, Spain, France, Norway and Sweden using the MARS. ${ }^{55}$ For patients from the Netherlands, adherence to maintenance therapy was assessed with the question, 'Do you ever forget your prevention inhalation medication?' Adherence was categorised as poor for responses of 'very often' or 'always'; borderline for responses of 'now and then' or 'regularly' and good for responses of 'never' or 'rarely'.

Patient-reported experiences during the inspiration phase of preventer inhaler use (i.e. feeling a sensation at the back of the throat, a need to cough and/or of medication being deposited at the back of the throat), side effects from preventer inhaler medications (i.e. continual sore mouth/ throat, oral thrush, bruising, hoarse voice, cough and abnormal weight gain) and the highest number of puffs of reliever inhaler taken in 1 day in the previous 4 weeks were recorded during the iHARP review on the patient-completed questionnaire.

Exacerbations were identified by one of the following patient-reported outcomes: hospital admission with breathing or chest problems; emergency department visit related to asthma; or an acute course (5-10 days) of oral corticosteroids for worsening asthma. The number of exacerbations was taken from the 12-month period preceding the iHARP review. 


\section{Data analysis}

Analyses were performed using SPSS (IBM ${ }^{\circledR}$ SPSS $^{\circledR}$ Statistics) Version 24. Characteristics of patients who accurately reported 'well-controlled' asthma (Group A) were compared to those of patients who inaccurately reported 'well-controlled' asthma (Group B). Continuous variables that were normally distributed were compared using Student's $t$ test and the Mann-Whitney $U$ test was used for continuous variables that were not normally distributed. Categorical variables were compared using Pearson's $X^{2}$ test. Univariable logistic regression models, with a dichotomised indicator variable (yes/no) as the dependent variable and each patient characteristic as an explanatory (or predictor) variable, were first used to identify characteristics associated with inaccurately reported 'well-controlled' asthma. Indicators of asthma symptoms and asthma control were not tested using univariable logistic regression because they were used to define the dependent variable. Intercorrelations among the predictor variables were then tested using Tolerance values, and those with high intercorrelations were not included in subsequent analyses. Demographic and clinical characteristics associated with inaccurately reported 'wellcontrolled' asthma in the univariable model $(p<0.05)$ were then entered into a multivariable regression model to produce a final list of non-collinear independently associated variables. Interactions between different variables were tested, and those that did not improve the model were not included. The goodness of fit of the logistic regression model was confirmed by the Hosmer and Lemeshow test. A two-tailed significance level of 0.05 was used for all statistical procedures.

\section{DATA AVAILABILITY}

The data that support the findings of this study are available from the corresponding upon reasonable request.

Received: 22 May 2019; Accepted: 8 November 2019; Published online: 05 December 2019

\section{REFERENCES}

1. Global Asthma Network (GAN). The Global Asthma Report (2018). www. globalasthmareport.org/Global\%20Asthma\%20Report\%202018.pdf.

2. European Lung white book (2018). www.erswhitebook.org/chapters.

3. Global Initiative for Asthma. Pocket Guide for Asthma Management and Prevention (2018). www.ginasthma.org/2018-pocket-guide-for-asthma-management-andprevention.

4. British Thoracic Society. BTS/SIGN British Guidelines on the Management of Asthma (2016). www.brit-thoracic.org.uk/standards-of-care/guidelines/btssign-britishguideline-on-the-management-of-asthma.

5. Pavord, I. D. et al. The impact of poor asthma control among patients treated with inhaled corticosteroids plus long-acting $\beta 2$ agonists in the United Kingdom: a cross-sectional analysis. npj Prim. Care Respir. Med. 27, 17 (2017).

6. Demoly, P., Annunziata, K., Gubba, E. \& Adamek, L. Repeated cross-sectional survey of patient-reported asthma control in Europe in the past 5 years. Eur. Respir. Rev. 21, 66-74 (2012).

7. Demoly, P., Gueron, B., Annunziata, K., Adamek, L. \& Walters, R. D. Update on asthma control in five European countries: results of a 2008 survey. Eur. Respir. Rev. 19, 150-157 (2010).

8. Reddel, H. K. et al. A summary of the new GINA strategy: a roadmap to asthma control. Eur. Respir. J. 46, 622-639 (2015).

9. Menzies-Gow, A. \& Chiu, G. Perceptions of asthma control in the United Kingdom: a cross-sectional study comparing patient and healthcare professionals' perceptions of asthma control with validated ACT scores. npj Prim. Care. Respir. Med. 27, 48 (2017).

10. Meltzer, E. O. et al. Asthma burden in the United States: results of the 2009 Asthma Insight and Management survey. Allergy Asthma Proc. 33, 36-46 (2012).

11. Murphy, K. R. et al. Asthma management and control in the United States: results of the 2009 Asthma Insight and Management survey. Allergy Asthma Proc. 33, 54-64 (2012).

12. Thompson, P. J. et al. Insights, attitudes and perceptions about asthma and its treatment: findings from a multinational survey of patients from 8 Asia-Pacific countries and Hong Kong. Respir 18, 957-967 (2013).

13. Maspero, J. F. et al. Insights, attitudes and perceptions about asthma and its treatment: findings from a multinational survey of patients from Latin America. World. Allergy. Organ. J. 6, 19 (2013).
14. Mintz, M. et al. Assessment of asthma control in primary care. Curr. Med. Res. Opin. 25, 2523-2531 (2009).

15. Nathan, R. A. et al. Taking aim at asthma around the world: global results of the Asthma Insight and Management survey in the Asia-Pacific region, Latin America, Europe, Canada, and the United States. J. Allergy Clin. Immunol. Pract. 3, 734-742 (2015).

16. Reddel, H., Sawyer, S. M., Everett, P. W., Flood, P. V. \& Peters, M. J. Asthma control in Australia: a cross-sectional web-based survey in a nationally representative population. Med. J. Aust. 202, 492-496 (2015).

17. Sastre, J. et al. Insights, attitudes, and perceptions about asthma and its treatment: a multinational survey of patients from Europe and Canada. World Allergy Organ. J. 9, 13 (2016).

18. Price, D., Fletcher, M. \& van der Molen, T. Asthma control and management in 8,000 European patients: the REcognise Asthma and LInk to Symptoms and Experience (REALISE) survey. npj Prim. Care. Respir. Med. 24, 14009 (2014).

19. Price, D. et al. Times for a new language for asthma control: results from REALISE Asia. J. Asthma Allergy 8, 93-103 (2015).

20. Chapman, K. R., Boulet, L. P., Rea, R. M. \& Franssen, E. Suboptimal asthma control: prevalence, detection and consequences in general practice. Eur. Respir. J. 31, 320-325 (2008).

21. Bosnic-Anticevich, S. et al. Lack of asthma and rhinitis control in general practitioner-managed patients prescribed fixed-dose combination therapy in Australia. J. Asthma 55, 684-694 (2018).

22. Accordini, S. et al. The cost of persistent asthma in Europe: an international population-based study in adults. Int. Arch. Allergy Immunol. 160, 93-101 (2013).

23. Nguyen, H. V. et al. Association between asthma control and asthma cost: Results from a longitudinal study in a primary care setting. Respiration 22, 454-459 (2017).

24. Fletcher, M. \& Hiles, D. Continuing discrepancy between patient perception of asthma control and real-world symptoms: a qualitative online survey of 1,083 adults with asthma from the UK. Prim. Care. Respir. J. 22, 431-438 (2013).

25. Laforest, L. et al. Asthmatic patients' poor awareness of inadequate disease control: a pharmacy-based survey. Ann. Allergy Asthma Immunol. 98, 146-152 (2007).

26. Bellamy, D. \& Harris, T. Poor perceptions and expectations of asthma control: results of the International Control of Asthma Symptoms (ICAS) survey of patients and general practitioners. Prim. Care. Respir. J. 14, 252-258 (2005).

27. Holgate, S. T., Price, D. \& Valovirta, E. Asthma out of control? A structured review of recent patient surveys. BMC Pulm. Med. 6(Suppl 1), 52 (2006).

28. Schatz, M. Predictors of asthma control: what can we modify? Curr. Opin. Allergy Clin. Immunol. 12, 263-268 (2012).

29. Braido, F. Failure in asthma control: reasons and consequences. Scientifica 2013, 549252 (2013).

30. Smits, D., Brigis, G., Pavare, J., Maurina, B. \& Barengo, N. C. Factors related to poor asthma control in Latvian asthma patients between 2013 and 2015. Scan. J. Prim. Health Care. 35, 186-191 (2017).

31. George, M., Keddem, S., Barg, F. K., Green, S. \& Glanz, K. Urban adults' perceptions of factors influencing asthma control. J. Asthma 52, 98-104 (2015).

32. Sims, E., Price, D., Haughney, J., Ryan, D. \& Thomas, M. Current control and future risk in asthma management. Allergy Asthma Immunol. Res. 3, 217-225 (2011).

33. Partridge, M. R., van der Molen, T., Myrseth, S. E. \& Busse, W. W. Attitudes and actions of asthma patients on regular maintenance therapy: the INSPIRE study. BMC Pulm. Med. 6, 13 (2006).

34. iHARP database (2018). https://opcrd.co.uk/international-helping-asthma-in-reallife-patients-iharp/.

35. Price, D. et al. Asthma in Asia: physician perspectives on control, inhaler use and patient communications. J. Asthma 53, 761-769 (2016).

36. Horne, R. et al. Can asthma control be improved by understanding the patient's perspective? BMC Pulm. Med. 7, 8 (2007).

37. Price, D. B. et al. Inhaler errors in the CRITIKAL study: type, frequency, and association with asthma outcomes. J. Allergy Clin. Immunol. Pract. 5, 1071-1081 (2017).

38. Westerik, J. A. et al. Characteristics of patients making serious inhaler errors with a dry powder inhaler and association with asthma-related events in a primary care setting. J. Asthma 53, 321-329 (2016).

39. Hancox, R. J. et al. Bronchodilator tolerance and rebound bronchoconstriction during regular inhaled beta-agonist treatment. Respir. Med. 94, 767-771 (2000).

40. Hancox, R. J. Concluding remarks: can we explain the association of beta-agonists with aStanford RH, Shahsthma mortality? A hypothesis. Clin. Rev. Allergy Immunol. 31, 279-288 (2006).

41. Stanford, R. H., Shah, M. B., D'Sousa, A. O., Dhamane, A. D. \& Schatz, M. Shortacting $ß$-agonist use and its ability to predict future asthma-related outcomes. Ann. Allergy Asthma Immunol. 109, 403-407 (2012).

42. Suissa, S. et al. A cohort analysis of excess mortality in asthma and the use of inhaled beta-agonists. Am. J. Respir. Crit. Care Med. 149, 604-610 (1994).

43. Taylor, R. \& Hannah, D. Management of ß-agonist overuse: why and how? J. Allergy Clin. Immunol. 122, 836-838 (2008). 
44. Cockcroft, D. W. Clinical concerns with inhaled ß2-agonists. Clin. Rev. Allergy Immunol. 31, 197-207 (2006).

45. Sarnes, E. et al. Incidence and US costs of corticosteroid-associated adverse events: a systematic literature review. Clin. Therap. 33, 1413-1432 (2011).

46. Waljee, A. K. et al. Short term use of oral corticosteroids and related harms among adults in the United States: population based cohort study. BMJ 357, j1415 (2017).

47. Dougherty, R. H. \& Fahy, J. V. Acute exacerbations of asthma: epidemiology, biology and the exacerbation-prone phenotype. Clin. Exp. Allergy 39, 193-202 (2009).

48. Price, D., Bjermer, L., Bergin, D. A. \& Martinez, R. Asthma referrals: a key component of asthma management that needs to be addressed. J. Asthma Allergy 10, 209-223 (2017).

49. The International Primary Care Respiratory Group (2018). www.theipcrj.org.

50. Quality and Outcomes Framework (2018). www.hscic.gov.uk/qof.

51. Global Initiative for Asthma. Global Strategy for Asthma Management and Prevention (Revised 2010). www.ginasthma.org.

52. Bousquet, J. et al. Ilergic Rhinitis and its Impact on Asthma (ARIA) 2008 update (in collaboration with the World Health Organization, GA(2)LEN and AllerGen. Allergy 63, 8-160 (2008).

53. Price, D. et al. International Primary Care Respiratory Group (IPCRG) Guidelines: management of allergic rhinitis. Prim. Care Respir. J. 15, 58-70 (2006).

54. Horne, R., Weinman, J. \& Hankins, M. The Beliefs about Medicines Questionnaire: the development and evaluation of a new method for assessing the cognitive representation of medication. Psychol. Health 14, 1-24 (1999).

55. Horne, R. \& Weinman, J. Self-regulation and self-management in asthma: exploring the role of illness perceptions and treatment beliefs in explaining nonadherence to preventer medication. Psychol. Health 17, 17-32 (2002).

\section{ACKNOWLEDGEMENTS}

The International Primary Care Respiratory Group (IPCRG) has facilitated the publication of this paper. The iHARP database was funded by unrestricted grants from Mundipharma International Limited and Optimum Patient Care Global Ltd, which is a social enterprise that focuses on quality improvement in clinical practice. The sponsor was not involved in data analysis or the interpretation of the results.

\section{AUTHOR CONTRIBUTIONS}

V.K. and S.B.-A. developed the research hypothesis, research aim and methodology for data analysis. V.K. extracted the data from the dataset, performed all statistical analyses and drafted the manuscript. S.B.A. critically revised the manuscript. All authors had intellectual input into the concepts explored, critically reviewed each draft of the full manuscript and approved the final version.

\section{COMPETING INTERESTS}

V.K. has received honoraria from AstraZeneca, GlaxoSmithKline and Pfizer, outside the submitted work. D.P. has board membership with Aerocrine, Amgen, AstraZeneca, Boehringer Ingelheim, Chiesi, Mylan, Mundipharma, Napp, Novartis, Regeneron Pharmaceuticals, Sanofi Genzyme, Teva Pharmaceuticals; consultancy agreements with Almirall, Amgen, AstraZeneca, Boehringer Ingelheim, Chiesi, GlaxoSmithKline, Mylan, Mundipharma, Napp, Novartis, Pfizer, Teva Pharmaceuticals, Theravance; grants and unrestricted funding for investigator-initiated studies (conducted through Observational and Pragmatic Research Institute Pte Ltd) from Aerocrine, AKL Research and Development Ltd, AstraZeneca, Boehringer Ingelheim, British Lung Foundation, Chiesi, Mylan, Mundipharma, Napp, Novartis, Pfizer, Regeneron Pharmaceuticals, Respiratory Effectiveness Group, Sanofi Genzyme, Teva Pharmaceuticals, Theravance, UK National Health Service, Zentiva (Sanofi Generics); payment for lectures/speaking engagements from Almirall, AstraZeneca, Boehringer Ingelheim, Chiesi, Cipla, GlaxoSmithKline, Kyorin, Mylan, Merck, Mundipharma, Novartis, Pfizer, Regeneron Pharmaceuticals, Sanofi Genzyme, Skyepharma, Teva Pharmaceuticals; payment for manuscript preparation from Mundipharma, Teva Pharmaceuticals; payment for the development of educational materials from Mundipharma, Novartis; payment for travel/accommodation/meeting expenses from Aerocrine, AstraZeneca, Boehringer Ingelheim, Mundipharma, Napp, Novartis, Teva Pharmaceuticals; funding for patient enrolment or completion of research from Chiesi, Novartis, Teva Pharmaceuticals, Zentiva (Sanofi Generics); stock/stock options from AKL Research and Development Ltd, which produces phytopharmaceuticals; owns $74 \%$ of the social enterprise Optimum Patient Care Ltd (Australia and UK) and 74\% of Observational and Pragmatic Research Institute Pte Ltd (Singapore); and is peer reviewer for grant committees of the Efficacy and Mechanism Evaluation programme, and Health Technology Assessment. A.P. is on the boards for and has received research and travel support and consultancy and lecture fees from Chiesi Farmaceutici, AstraZeneca, GlaxoSmithKline, Boehringer Ingelheim, Merck Sharp \&
Dohme, Takeda, Mundipharma Research Limited and Teva; has received lecture fees and travel support from Menarini, Novartis and Zambon; is on the boards for and has received lecture fees and travel support from Pfizer, and has received research support from Sanofi. B. Ställberg has received honoraria for educational activities and lectures from AstraZeneca, Boehringer Ingelheim, GlaxoSmithKline, Meda, MSD, Novartis and Teva, and has served on advisory boards arranged by GlaxoSmithKline, AstraZeneca, Novartis, Meda and Boehringer Ingelheim. D.R. has received consultancy fees from Chiesi, Teva, Novartis and Boehringer Ingelheim; fees from advisory boards from Teva, Chiesi, Boehringer Ingelheim and Novartis; has received lecture fees from Takeda, AstraZeneca and Meda; has received payment for educational presentations from Meda; is European Academy of Allergy and Clinical Immunology chair of primary care interest group; is Director of Respiratory Effectiveness Group; and is Strategic Clinical Director for Optimum Patient Care. F. L. has received honoraria for consultancy and presentations from Cipla, Almirall, AstraZeneca, Boehringer Ingelheim, Chiesi, Menarini International, Teva and Zentiva. H.C. has no shares in any pharmaceutical companies; is employed by RiRL, which is subcontracted by Observational and Pragmatic Research Institute Pte Ltd; has received sponsorship to carry out studies, together with board membership, consultancy agreements, and honoraria for presentation for Almirall, AstraZeneca, Boehringer Ingelheim, Chiesi, GlaxoSmithKline, Innovata, Biomed, Meda, Napp Pharmaceuticals, Mundipharma Research Limited, NorPharma, Novartis, Orion, Sanof, Teva, Truddell Medical International, UCB and Zentiva; and owns 50\% of Inhalation Consultancy Ltd. J.H. has received reimbursements for attending symposia, fees for speaking, organising educational events, funds for research or fees for consulting from Cipla, AstraZeneca, Boehringer Ingelheim, GlaxoSmithKline, Merck Sharpe \& Dohme, Mundipharma Research Limited and Novartis, and T.K.L. is on the boards for Novartis and Meda; is on the scientific committee for AstraZeneca and Novartis; has received lecture fees from AstraZeneca, GlaxoSmithKline, meda, Nycomed, Boehringer Ingelheim and Novartis; has received payment for developing educational presentations from Novartis; and is on the steering committees for AstraZeneca and Novartis. K.G.-J. declares speaking engagements and consultancy for AstraZeneca, GlaxoSmithKline, Boehringer Ingelheim, Mundipharma and Novartis. M.R.-R. has received personal fees from Almirall, AstraZeneca, GlaxoSmithKline, Boehringer Ingelheim, Chiesi, Menarini, Mundipharma Research Limited, Novartis, Pfizer, Rovi, Teva and Gebro and has received research support from personal fees from GlaxoSmithKline. T.v.d.M. has received grants for research, travel fees and reimbursement for presentations and advisory boards from AstraZeneca, GlaxoSmithKline, Almirall, Mundipharma Research Limited, Boehringer Ingelheim, Chiesi, Teva and Novartis and is on the Certe Laboratories board. V.C. is an employee of Optimum Patient Care Ltd and Observational and Pragmatic Research Institute Pte Ltd. S.B.-A. has received payment for lectures, expert advice and independent research from Teva, AstraZeneca, Boehringer Ingelheim, GlaxoSmithKline, Mundipharma, Mylan and Sanofi, outside the submitted work. The rest of the authors declare no competing interests.

\section{ADDITIONAL INFORMATION}

Supplementary information is available for this paper at https://doi.org/10.1038/ s41533-019-0156-4.

Correspondence and requests for materials should be addressed to V.K.

Reprints and permission information is available at http://www.nature.com/ reprints

Publisher's note Springer Nature remains neutral with regard to jurisdictional claims in published maps and institutional affiliations.

Open Access This article is licensed under a Creative Commons Attribution 4.0 International License, which permits use, sharing, adaptation, distribution and reproduction in any medium or format, as long as you give appropriate credit to the original author(s) and the source, provide a link to the Creative Commons license, and indicate if changes were made. The images or other third party material in this article are included in the article's Creative Commons license, unless indicated otherwise in a credit line to the material. If material is not included in the article's Creative Commons license and your intended use is not permitted by statutory regulation or exceeds the permitted use, you will need to obtain permission directly from the copyright holder. To view a copy of this license, visit http://creativecommons. org/licenses/by/4.0/.

(c) The Author(s) 2019 